Research Article

\section{Physical activity and health- related quality of life among physiotherapists in Hebron/West \\ Bank}

\section{Mouath D Abushkadim¹, Akram Amro² and Muntaser S Ahmad $^{3 *}$}

'Department of Physiotherapy, Faculty of Applied Medical Health, Palestine Ahliya University, Dheisha, Bethlehem, Palestine

${ }^{2}$ Department of Physiotherapy, Faculty of Health Professions, Al-Quds University, Jerusalem, Palestine

${ }^{3}$ Department of Medical Imaging, Faculty of Applied Medical Health, Palestine Ahliya University, Dheisha, Bethlehem, Palestine

\section{Abstract}

Introduction: Physical activity (PA) directly affects Health-related quality of life. The aim of the study was to establish the relationship between physical activity levels of physiotherapists and their physical activity promotion strategies. in Hebron/West Bank.

Method: The study relied on cross-section, which included 150 PTs distributed over 42 centers of Hebron areas in Palestine country. The questionnaire is based on Likert scale items pentagonal level, which included several aspects of Health-related quality of life. Statistical analysis was used to test the associations between different categorical variables $(p<0.05)$.

Results: of total 150 participants, most of them were male $56 \%$, their ages ranged from 25 30 years $(46 \%)$, and holding bachelor's degrees $78 \%$. About $60 \%$ of them are in good physical health. Most participants feel vitality, depression, quit, have energy, and are happy in the most of the time. In addition, most of them believe their health is similar to that of the members of the surrounding community. The study showed there is no relationship between general health and age except in the age group over 40 years, and females are the most exposed group. In addition, there is an influence relationship between physical and psychological with age, and this effect also includes females more than males.

Conclusion: Physical functioning of most of the participants was good, while most of the participants had problems with their work and the major effect was on the female category.

\section{More Information}

*Address for Correspondence: Muntaser S Ahmad, Ph.D Candidate, Department of Medical Imaging, Faculty of Applied Medical Health, Palestine Ahliya University, Dheisha, Bethlehem, Palestine, Telephone: +970595107857; Email: wmuntaser@gmail.com

Submitted: 30 June 2018

Approved: 10 July 2020

Published: 13 July 2020

How to cite this article: Abushkadim MD, Amro A, Ahmad MS. Physical activity and healthrelated quality of life among physiotherapists in Hebron/West Bank. J Nov Physiother Rehabil. 2020; 4: 022-027.

DOI: 10.29328/journal.jnpr.1001033

ORCiD: orcid.org/0000-0002-4340-7252

Copyright: @ 2020 Abushkadim MD, et al. This is an open access article distributed under the Creative Commons Attribution License, which permits unrestricted use, distribution, and reproduction in any medium, provided the original work is properly cited.

Keywords: Physical activity; Physical functioning; Physical and psychological health; HRQOL

(D) Check for updates

OPEN ACCESS

\section{Introduction}

Physical activity (PA) is defined as the consumption of energy in muscle contraction, which leads to movement of the body. PA is closely related to the musculoskeletal muscle fitness that affects the health prevention strategies [1,2]. PA is an essential tool in preventing movement disorders and chronic disabilities $[3,4]$.

Early on in Physiotherapists (PTs) career, many physiotherapists drop out of their jobs or at least drop out of clinical work [5][6]. Many factors contribute to the attrition of physiotherapists, including raising a family and further education [7]. In addition to the burnout phenomenon and their related with physical activity [8,9]. Moreover, several studies have shown disorders in PA have a major impact on the longevity of physiotherapists work as well as the effect on health-related quality of life [10].

The disorders affect PTs with little experience compared to those with significant experience. The PT needs a lot of manual force to perform manual therapy, which further develops musculoskeletal problems [11]. Previous studies have shown that musculoskeletal disorders has a clear effect on the physiotherapistss work during a range of clinical settings [12-14]. 
The PTs health is also affected by the private lifestyle they live in, which affects their job performance, and thus in turn affects health care services. Therefore, the demand for monitoring these services increases through quality control and quality management. Because the profession of PTs deals with physical activity directly, many studies have shown the health care workers play a key role in fighting physical inactivity [15]. physical inactivity affects the PTs on selfconfidence, social attitudes, mental health, and perceived stress [16]. Because PA is important in the professional life of a PT, it is important to know the PA and its role in influencing health-related quality of life. Therefore, the aim of the study was to establish the physical activity levels of physiotherapists in Hebron-West Bank and their physical activity health promotion practices.

\section{Methods and materials}

\section{Study design}

This study was based on a cross section of PTs. It was conducted at different physiotherapy centers in Hebron, Palestine, after the ethical approval of those centers was obtained. The study sample was 150 PTs across 42 different physiotherapy centers.

\section{Participants and setting}

The study was based on PTs who worked for more than 6 hours daily. The study excluded any PTs who did not work at least 6 hours daily, or those with any disability or musculoskeletal disorder.

\section{Measurements}

The data was collected using the SERVQUAL questionnaire. The questionnaire includes information about the PTs, which includes gender, age, and educational qualification. The study tool used was a health survey form represented in Short Form- 36 (SF-36). The questionnaire measures several mental and physical health aspects, including general health, physical functioning, body pain, emotional problem, and selfknowledge for the body health.

The questionnaire was built on the Likert scale items, the service quality is measured by five grades, starting with strongly disagree, disagree, neutral, agree, and strongly agree.

\section{Data analysis}

A SPSS 10.0.1174 software was used for data analysis. Tables were used to express descriptive analysis, While the bar chart was used to represent figures. Data and information analysis were based on the use of three tests: Descriptive statistics, Pearson correlation, and Mann- Whitney U test.

\section{Results}

The reliability of the data collection questionnaire was measured using Cronbach's Alpha test $76.4 \%$. This value is good enough for the reliability to take the current results.
A total 150 of participants are collected in this study. The PT centers were divided into 42 centers. Demographic information was analyzed descriptively (number and percentage) and presented in table 1.

The results showed that $56 \%$ of the participants were males and $44 \%$ of them were female. It is also shown that the majority of the participants (46\%) are between the ages of 25 and 30 years, and the minority are between the ages of 35 and 40 years. In the same table, we also can see that most of the participants (78\%) have a bachelor's degree. However, the minority (4\%) have Ph.D.

\section{General health}

Table 2 shows the general health of the participants. It was distributed into four groups; excellent; very good; good; and not bad. As shown in table 2, 60\% of the participants have very good health in general. While the majority of participants $(48 \%)$ reported that they were no different than the previous year. However, $12 \%$ of the participants reported that their health is currently better than it was in the previous year.

\section{Physical functioning}

Physical functioning was measured in this study and consisted of nine sections. Figure 1 shows these aspects and the main differentiation in each section.

As shown on figure 1, 36\% of the participants agreed that there are limitations to doing vigorous activities, such as running, lifting heavy objects, or participating in strenuous sports. However, $8 \%$ of the participants disagreed.

Regarding moderate activities, $22 \%$ of the participants reported that their health currently limits their ability to do moderate activities, such as moving a table, pushing a vacuum cleaner. However, most participants - 32\% - reported that their physical activity was not reduced.

\begin{tabular}{|c|c|c|c|}
\hline \multicolumn{4}{|c|}{ Total respondents } \\
\hline \multirow{2}{*}{ Gender } & Male & 84 & $56.0 \%$ \\
\hline & Female & 66 & $44.0 \%$ \\
\hline \multirow{5}{*}{ Age } & $20-25$ & 36 & $24.0 \%$ \\
\hline & $25-30$ & 69 & $46.0 \%$ \\
\hline & $30-35$ & 18 & $12.0 \%$ \\
\hline & $35-40$ & 12 & $8.0 \%$ \\
\hline & $>40$ & 15 & $10.0 \%$ \\
\hline \multirow{4}{*}{ Level of education } & diploma & 15 & $10.0 \%$ \\
\hline & bachelor & 117 & $78.0 \%$ \\
\hline & master & 12 & $8.0 \%$ \\
\hline & Ph.D & 6 & $4.0 \%$ \\
\hline
\end{tabular}

Table 2: The distribution of general health in the sample.

\begin{tabular}{|c|c|c|c|}
\hline \multirow{3}{*}{ General health } & \multicolumn{2}{|c|}{ Total respondents } \\
\cline { 2 - 4 } & Excellent & 33 & $22.0 \%$ \\
\cline { 2 - 4 } & Very good & 90 & $60.0 \%$ \\
\hline \multirow{3}{*}{ General health now } & Good & 24 & $16.0 \%$ \\
\hline & not bad & 3 & $2.0 \%$ \\
\hline & best than previous year & 24 & $16.0 \%$ \\
\hline & better than previous year & 18 & $12.0 \%$ \\
\hline & no differences than previous year & 72 & $48.0 \%$ \\
\hline & bad than previous year & 36 & $24.0 \%$ \\
\hline
\end{tabular}




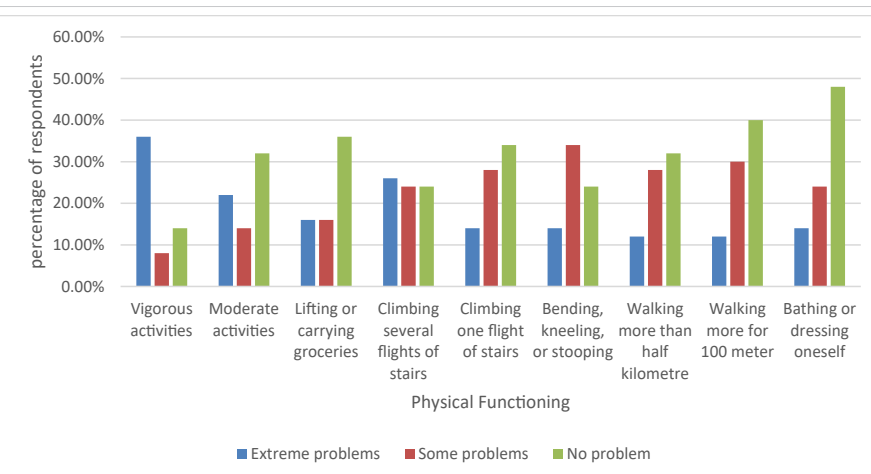

Figure 1: The distribution of physical functioning through the participants.

Regarding lifting and carrying groceries, $36 \%$ of the participants reported they could do these activities without difficulty. The results also showed a fluctuation between participants and their ability to walk up the stairs for several floors without any problem. In addition to that, the majority of participants (62\%) do not have any problem going up one flight of stairs.

In the same figure, we can see that most participants (34\%) don't have problems when bending, kneeling, or stooping. But $12 \%$ do have problems with these actions. Regarding the ability to walk half a kilometer, the results showed that the majority of participants could walk this distance without problems, while $8 \%$ reported problems with the ability to walk such a distance. Moreover, most of the participants reported they can walk 100 meters without any difficulties, and this result supports the previous result. Finally, the results show that the participants are able to take a shower and dress themselves unaided.

\section{Physical health}

To measure Physical health, the researcher made a yes or no question with five sections; cut down the amount of time one spent on work; accomplished less than you would like; limitation in kind of work; difficulty performing work; Complete an activity. Figure 2 shows the results of these questions.

The results shown are the participants reports of any

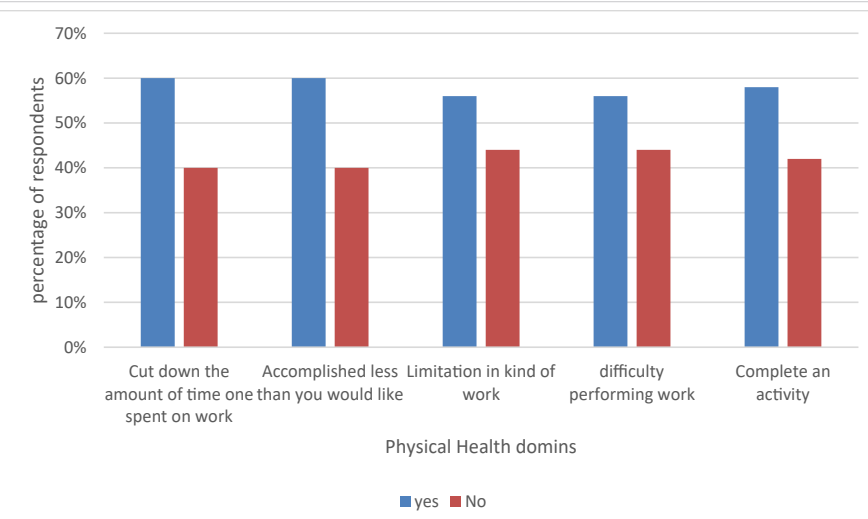

Figure 2: The participants physical health distribution in the sample. difficulties that physiotherapists may suffer during their normal daily activities as a result of their physical and mental health over the past month. Figure 2 shows that most of the participants agreed that they were facing difficulties in their daily work.

\section{The body pains}

In this study, body pain was divided into four sections: physical and psychological health; the body pain; pain effects; and the effect of the pain on social functioning. Figure 3 demonstrates all of these differentiate.

As the Figure 3 shows, $34 \%$ of the participants reported little difference in health problems affecting their normal social activities. We can also see that the majority of participants reported they had no pain over the past 4 weeks. However, more than $45 \%$, making the majority, reported pain, but at the same time, the participants reported that the pain did not affect their social activities.

\section{Emotional problem}

Emotional problems were measured by using 9 questions which examined: activity and vitality; nervous person; depression; quiet and safe; energy; frustration; exhausted; happy person; and tired. Figure 4 demonstrates the main results for this section.

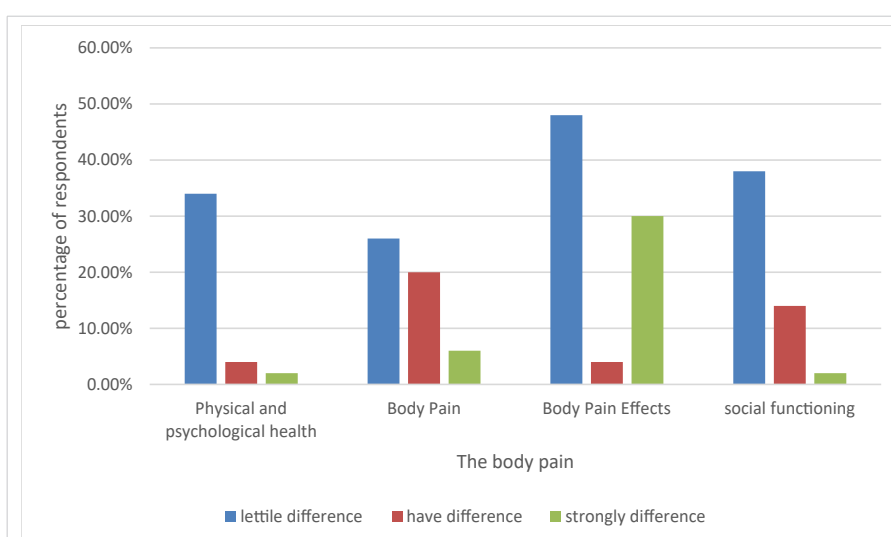

Figure 3: The distribution of the body pain and their effects on the social, physical, and psychological health on the PTs participants.

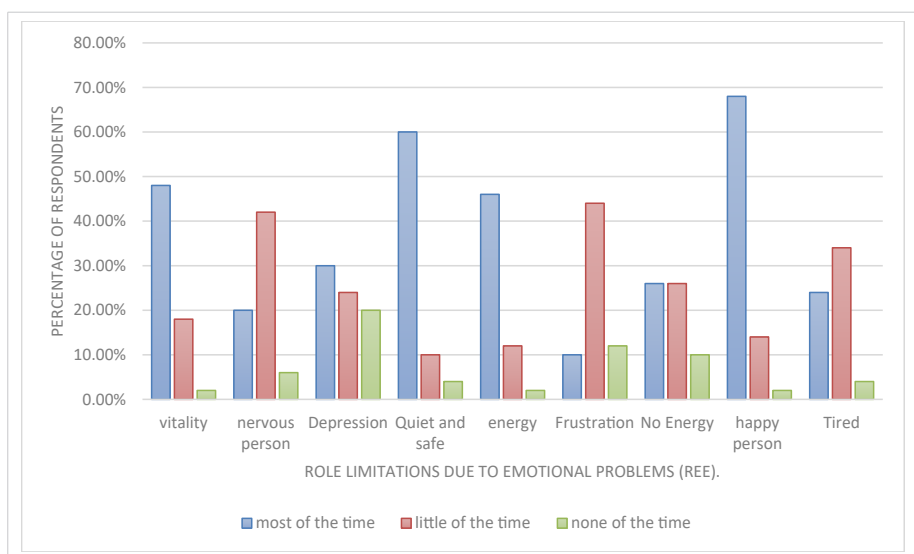

Figure 4: The effects of emotional problems on the physiotherapists. 
As shown in figure 4, most of the participants felt vitalized, at the same time they did not feel angry most of the time. However, most of the participants reported feeling depressed at work during the past 4 weeks.

In addition, the majority of the participants reported feeling calm and safe at work. Moreover, most of them reported having energy. However, they reported that some of the time they felt frustration and fatigue. Despite that, most of them feel happy when working, while also feeling tired a little of the time.

\section{Self-knowledge for the body health}

The study also examined the self-knowledge of the participants of their body health. The results show that most of participants had a good level of knowledge of their own body health.

Figure 5 shows the most of participants disagreed that the racetrack was easier for them than others, while most of them agreed that their health was equal to that of the others. Regarding predicting how much their health would worsen, most of the participants agreed that their health had improved, and this is supported by the result of the last question where most of the participants reported their health was excellent.

The correlation between of physical health on the physiotherapist's daily work

The relationship between age and activities in daily life was measured using Pearson correlation. The correlation in table 3 shows there are no significant differences between both age and ADL.

\section{The correlation between age and general health}

To confirm the previous result, the relationship between

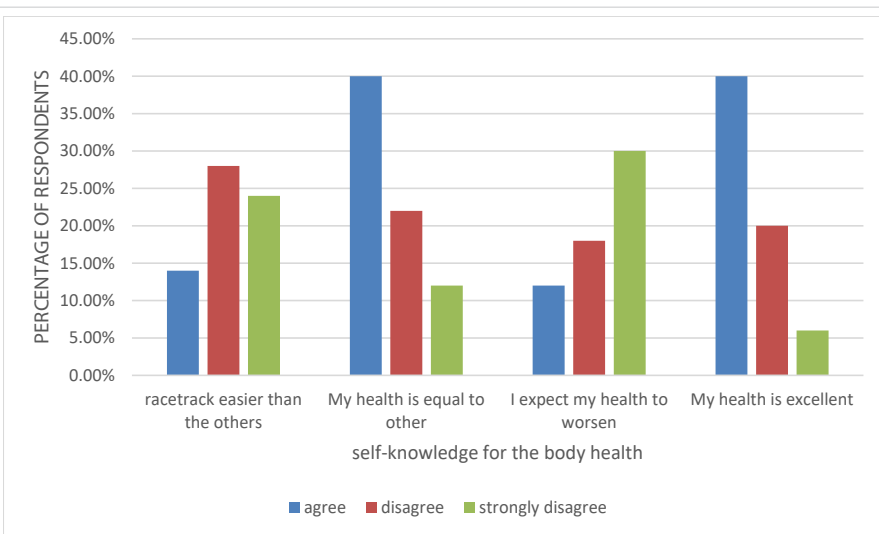

Figure 4: Self-knowledge of the physiotherapist body health.

Table 3: The effect of physical health on the physiotherapist's daily work.

\begin{tabular}{|c|c|c|}
\multicolumn{2}{c}{$\begin{array}{c}\text { Correlations between age and difficulty in performing } \\
\text { ADL }\end{array}$} & $\begin{array}{r}\text { difficulty in } \\
\text { performing ADL }\end{array}$ \\
\hline \multirow{2}{*}{ Age } & Pearson Correlation & -0.177 \\
\cline { 2 - 3 } & Sig. (2-tailed) & 0.220 \\
\hline & N & 150 \\
\hline
\end{tabular}

general health and different age groups was assessed using the Pearson correlations.

Table 4 illustrates there are no significant differences between the age and general health of the participants, except in those aged over 40 , where we see a significant difference in their general health. However, the small sample size does not indicate this result can apply as a general result for all participants.

\section{The correlation between body pain and general health}

The pain or discomfort considered the biggest contributing factor on the general health of the physiotherapists, despite the small portion of participants who reported this. However, the analysis shows there is a significant difference between them with Sig. (2-tailed) 0.006 which is less than 0.05 . These results are shown in table 4 .

The correlation between the general health and the gender of physiotherapists

Using the none parametric Mann Whitney test, table 5 shows there is statistically significant difference between males and females in relation to general health $p<0.05$.

The correlation between physical and psychological health and the gender of physiotherapists

The correlation between gender and physical and psychological state was investigated using Mann- Whitnev U test. The result show there is no significant difference between physical and psychological state and gender with sig tailed equal to 0.457 which is more than 0.05 . This result shown in table 5 .

Table 4: The effect of general health on the age and body pain of physiotherapists.

\begin{tabular}{|c|c|c|c|c|}
\hline $\begin{array}{c}\text { Correlations between general health } \\
\text { and age group }\end{array}$ & Age 25-30 & Age $>\mathbf{4 0}$ & Mean Age \\
\hline \multirow{2}{*}{ General Health } & $\begin{array}{c}\text { Pearson } \\
\text { Correlation }\end{array}$ & 1 & -0.177 & 0.188 \\
\cline { 2 - 4 } & Sig. (2-tailed) & 0.782 & 0.041 & 0.191 \\
\cline { 2 - 4 } & $\mathrm{N}$ & 69 & 15 & 150 \\
\hline Correlations between Mean pain and general health & \multicolumn{2}{c|}{ Mean pain } \\
\hline \multirow{2}{*}{ General Health } & Pearson Correlation & \multicolumn{2}{|c|}{$0.386^{* *}$} \\
\cline { 2 - 4 } & Sig. (2-tailed) & \multicolumn{2}{c|}{0.006} \\
\hline Total respondents & $\mathrm{N}$ & 150 \\
\hline
\end{tabular}

Table 5: The correlation between gender of physiotherapists and general health, physical and psychological health of physiotherapists.

\begin{tabular}{|l|c|c|c|}
\hline \multirow{3}{*}{ General health } & Gender & N & Mean Rank \\
\hline & Male & 84 & 22.05 \\
\cline { 2 - 4 } & Female & 66 & 29.89 \\
\cline { 2 - 4 } & Total & 150 & \\
\hline \multirow{3}{*}{ Physical and psychological health } & Sig. (2-tailed) & 0.032 & \\
\hline & gender & $\mathbf{N}$ & Mean Rank \\
\hline & male & 84 & 2.39 \\
\hline & female & 66 & 2.18 \\
\cline { 2 - 4 } & Total & 150 & \\
\hline & Sig. (2-tailed) & 0.457 & \\
\hline
\end{tabular}


The correlation between physical and psychological and the age of physiotherapists

The physical and psychological health was measured using the average of three variables including physical pain, and psychological and social aspects. Using the Pearson correlation test there was a statistically significant positive correlation between these aspects and age. It seems that age negatively affects the psychological health $p<0.05$. These results are shown in table 6.

Table 6: The correlation between physical and psychological health and the age of physiotherapists.

\begin{tabular}{|c|c|c|}
\hline \multicolumn{2}{|c|}{$\begin{array}{l}\text { Correlations between age and physical and } \\
\text { psychological }\end{array}$} & $\begin{array}{c}\text { physical and } \\
\text { psychological domains }\end{array}$ \\
\hline \multirow{3}{*}{ Age } & Pearson Correlation & $0.282^{*}$ \\
\hline & Sig. (2-tailed) & 0.047 \\
\hline & $\mathrm{N}$ & 150 \\
\hline
\end{tabular}

\section{Discussion}

Physical activity consists of four aspects: the physiological aspect, the psychological aspect, the social aspect, and the development aspect [17]. Physical activity directly affects Health-related quality of life (HRQOL). The HRQOL system is validated in several respects, which includes the four aspects previously mentioned [18]. Physical activity affects physiotherapists, which in turn affects their HRQOL system [19]. The study showed that Most participants feel vitality, depression, quit, have energy, and are happy in the most of the time. In addition, most of them believe their health is similar to that of the members of the surrounding community. The female group more affected than man physical and psychological with their age.

The current investigation indicates that most of PTs in the current sample were already in a good state of health physical activities and this result supported the hypothesis of the study. The physical activities included walking and vigorous activities such as running, lifting heavy objects, and strenuous sports. Our results show that there is not a clear difference between age and the physiotherapist's daily work have not a clear difference. This result is consistent with previous studies [20-22].

In the younger age group, general health levels reported were very good compared with that of older PTs. The significant difference was the older participants' general health as shown in this study. This result was considerably better health-related quality than previous study which was done in Australia $[23,24]$. In general, the general health of the participants in the same age group is considered very good.

The current study appears to show that the male participants have better health in general compared to the female participants. This significant difference was similar to Éva works [25], who shows that the female physiotherapist unlike to the males which experienced higher stress compared to their peers in the general population especially in resilience and psychological morbidity. In the same field the study was focused on the correlation between gender and physical and psychological health. As shown in the below section males psychological and physical health is better than females. Even though this difference was not statistically significant $(p>.05)$. In another study which was conducted by Campo, et al. [26] showed female therapists were more likely than male therapists to suffer pain through works due to their job. Also, the female therapists were more likely to be less active whilst working. Also, there are different previous studies which show that male physiotherapists were reportedly in considerably in better general health than female physiotherapists [27-30].

Our study also showed there were no differences between male and female physiotherapists with regards to their physical and psychological health. However, this result was different to that found by Muadi, et al.[31] conducted, and the results of that study found there was a significant correlation between physical demands, work setting, BMI and gender.

Another study conducted in the society of Japan showed the younger participants were more physically active than their older counterparts, due to the difference in the lifestyles between them. The current study demonstrates similar results in the PTs community [32].

The current study was based on a cross-sectional analysis. Therefore, the cause-and-effect determination was not sufficiently accurate. In addition, the level of the effect of physical activity on the physiotherapists was determined by the self-reported questionnaire of, thus the extent of the effect cannot be accurately estimated. There is a need for future studies to be conducted to assess the effect of physical activity on HRQOL for physiotherapists in clinical and non-clinical practices

\section{Conclusion}

Physical activity of a physiotherapist affects HRQOL, which in turn affects their job performance. Physical functioning and psychological improvement increase the physical activity. The current study achieved its aims and gave a future vision about the situation facing the physiotherapists in Palestine and their job performance. Community-related characteristics must be understood to enhance the physical activity of this group.

\section{Disclosure}

The authors did not receive any type of commercial support in forms of either compensation or financial support for this study.

\section{References}

1. Frantz JM, Ngambare R. Physical activity and health promotion strategies among physiotherapists in Rwanda. African health sciences. 2013; 13: 17-23.

PubMed: https://www.ncbi.nlm.nih.gov/pubmed/23658563 
2. Abaraogu UO, Edeonuh JC, Frantz J. Promoting physical activity and exercise in daily practice: Current practices, barriers, and training needs of physiotherapists in eastern Nigeria. Physiother Can. 2016; 68: 37-45, 2016.

PubMed: https://www.ncbi.nlm.nih.gov/pmc/articles/PMC4961313/

3. Nordin NA, Leonard JH, Thye NC. Thye. Work-related injuries among physiotherapists in public hospitals-a Southeast Asian picture. Clinics. 2011; 66: 373-378.

PubMed: https://www.ncbi.nlm.nih.gov/pubmed/21552658

4. Alarab A, Shameh RA, Shaheen H, Ahmad MS. Shock Wave Therapy and Ultrasound Therapy plus Exercises for Frozen Shoulder Joint Clients. Adv Nurs patient care Int J. 2018; 1: 1-7.

PubMed: https://www.ncbi.nlm.nih.gov/pubmed/21552658

5. Schofield DJ, Fletcher SJ. The physiotherapy workforce is ageing becoming more masculinised, and is working longer hours: A demographic study. Aust J Physiother. 2007; 53: 121-126.

PubMed: https://pubmed.ncbi.nlm.nih.gov/17535148/

6. McMeeken J, Grant R, Webb G, Krause KL, Garnett R. Australian physiotherapy student intake in increasing and attrition remains lower than the university average: A demographic study. Aust. J. Physiother. 2008; 54: 65-71, 2008

PubMed: https://pubmed.ncbi.nlm.nih.gov/18298361/

7. Girbig M, Freiberg A, Deckert S, Druschke D, Kopkow C, et al Work-related exposures and disorders among physical therapists: experiences and beliefs of professional representatives assessed using a qualitative approach. J Occupat Med Toxicol. 2017; 12. PubMed: https://www.ncbi.nlm.nih.gov/pmc/articles/PMC5219788/

8. Lee MK, Kim E, Paik IS, Chung J, and S. M. Lee. Relationship between environmental factors and burnout of psychotherapists: Meta-analytic approach. Couns Psychother Res. 2020; 20: 164-172.

9. Shaheen H, Alarab A, Ahmad MS. Effectiveness of therapeutic ultrasound and kinesio tape in treatment of tennis elbow. J Nov Physiother Rehabil. 2019; 3: 25-33.

10. Ezzatvar Y, Calatayud J, Andersen LL, Aiguadé R, Benítez J, et al. Professional experience, work setting, work posture and workload influence the risk for musculoskeletal pain among physical therapists: a cross-sectional study. Int. Arch. Occup. Environ. Health.2020; 93: 189196, 2020. PubMed: https://www.ncbi.nlm.nih.gov/pubmed/31455983

11. Kotejoshyer R, Punnett L, Dybel G, Buchholz B. Claim Costs, Musculoskeletal Health, and Work Exposure in Physical Therapists, Occupational Therapists, Physical Therapist Assistants, and Occupational Therapist Assistants: A Comparison Among Long-Term Care Jobs. Phys Ther. 2018; 99: 183-193.

12. Anderson SP, Oakman J. Allied Health Professionals and WorkRelated Musculoskeletal Disorders: A Systematic Review. Saf. Health Work. 2016; 7; 259-267, 2016.

PubMed: https://pubmed.ncbi.nlm.nih.gov/27924228

13. Alnaser MZ. Occupational Therapy Practitioners with Occupational Musculoskeletal Injuries: Prevalence and Risk Factors. J Occup Rehabil. 2015; 25: 763-769.

PubMed: https://www.ncbi.nlm.nih.gov/pubmed/26044946

14. Darby B, Gallo AM, Fields W. Physical attributes of endoscopy nurses related to musculoskeletal problems. Gastroenterol. Nurs.2013; 36: 202-208.

PubMed: https://www.ncbi.nlm.nih.gov/pubmed/23732785

15. Verhagen E, Engbers L. The physical therapist's role in physical activity promotion. Br J Sports Med. 2009; 43: 99-101.

PubMed: https://pubmed.ncbi.nlm.nih.gov/18838405/

16. Vankim NA, Nelson TF. Vigorous physical activity, mental health, perceived stress, and socializing among college students. Am J Heal Promot. 2013; 28: 7-15.

PubMed: https://pubmed.ncbi.nlm.nih.gov/23470187/
17. Tremblay MS, Warburton DE, Janssen I, Paterson DH, Latimer AE, et al. New Canadian physical activity guidelines. Appl Physiol Nutr Metab. 2011; 36: 36-46

PubMed: https://pubmed.ncbi.nlm.nih.gov/21326376

18. Mapes DL, Bragg-Gresham JL, Bommer J, Fukuhara S, McKevitt $P$, et al. Health-related quality of life in the Dialysis Outcomes and Practice Patterns Study (DOPPS). Am J Kidney Dis. 44: 54-60. PubMed: https://pubmed.ncbi.nlm.nih.gov/15486875/

19. Brattig B, Schablon A, Nienhaus A, Peters C. Occupational accident and disease claims, work-related stress and job satisfaction of physiotherapists. J Occup Med Toxicol. 2014; 9: 1-13. PubMed: https://www.ncbi.nlm.nih.gov/pubmed/25505490

20. Bauman AE. Updating the evidence that physical activity is good for mental health: an epidemiological review 2000-2003. J Sci Med Sport. 2003; 7: 6-19.

PubMed: https://pubmed.ncbi.nlm.nih.gov/15214597/

21. Amin K, Hafeez S, Hassan D, Zahid S. Physical Activity and HealthRelated Quality of Life Among Physiotherapists. 51-55.

PubMed: https://www.ncbi.nlm.nih.gov/pmc/articles/PMC3896696/

22. Acree LS, Longfors J, Fjeldstad AS, Fjeldstad C, Schank B, et al. Physical activity is related to quality of life in older adults. Health and quality of life outcomes. 2006; 4: 37.

PubMed: https://www.ncbi.nlm.nih.gov/pubmed/16813655

23. Guallar-Castillón P, Santa-Olalla Peralta P, Banegas JR, López E. Physical activity and quality of life in older adults in Spain. Med. Clin. (Barc). 2004; 123: 606-610. PubMed: https://www.ncbi.nlm.nih.gov/pubmed/15546517

24. Viney R, Norman R, King MT, Cronin P, Street DJ, et al. Time trade-off derived EQ-5D weights for Australia. Value in Health. 2011; 14: 928-936. PubMed: https://pubmed.ncbi.nlm.nih.gov/21914515/

25. Bíró E, Veres-Balajti I, Kósa K. Social support contributes to resilience among physiotherapy students: A cross sectional survey and focus group study. Physiother. (United Kingdom). 2016; 102: 89-195. PubMed: https://pubmed.ncbi.nlm.nih.gov/26117566/

26. Campo MA, Weiser S, Koenig KL. Job Strain in Physical Therapists. Phys Ther. 2009; 89: 946-956.

PubMed: https://www.ncbi.nlm.nih.gov/pmc/articles/PMC2737052/

27. Hughes R. Summary for Policymakers. in Climate Change 2013 - The Physical Science Basis. 53, no. 9, Intergovernmental Panel on Climate Change, Ed. Cambridge: Cambridge University Press. 2008; 1-30.

28. Glover W, McGregor A, Sullivan C, Hague J. Work-related musculoskeletal disorders affecting members of the Chartered Society of Physiotherapy. Physiotherapy. 2005; 91: 138-147.

PubMed: https://www.ncbi.nlm.nih.gov/pmc/articles/PMC3038991/

29. Grooten WJA, Wernstedt P, Campo M. Work-related musculoskeletal disorders in female Swedish physical therapists with more than 15 years of job experience: Prevalence and associations with work exposures. Physiother. Theory Pract. 2011; 27: 213-222. PubMed: https://pubmed.ncbi.nlm.nih.gov/20690880/

30. Alghadir A, Zafar H, Iqbal ZA. Work-related musculoskeletal disorders among dental professionals in Saudi Arabia. J Phys Ther Sci. 2015; 27: 1107-1112.

PubMed: https://pubmed.ncbi.nlm.nih.gov/25995567/

31. Muaidi QI, Shanb AA. Effects of work demands on physical therapists in the KSA. J Taibah Univ Med Sci. 2016; 11: 56-62.

32. Brown DW, Balluz LS, Heath GW, Moriarty DG, Ford ES, et al. Associations between recommended levels of physical activity and health-related quality of life Findings from the 2001 Behavioral Risk Factor Surveillance System (BRFSS) survey. Preventive medicine. 2003; 37: 520-528. PubMed: https://pubmed.ncbi.nlm.nih.gov/14572437/ 